\title{
DÜBLIN
}

Technological University Dublin

ARROW@TU Dublin

\section{A new configuration and control of doubly fed induction generator (UPQC-WG)}

\author{
N. G. Jayanti \\ Technological University Dublin \\ Malabika Basu \\ Technological University Dublin, mbasu@tudublin.ie \\ Kevin Gaughan \\ Technological University Dublin, Kevin.Gaughan@tudublin.ie
}

See next page for additional authors

Follow this and additional works at: https://arrow.tudublin.ie/engscheleart

Part of the Electrical and Computer Engineering Commons

\section{Recommended Citation}

Jayanti, N. G. et al. : A new configuration and control of doubly fed induction generator (UPQC-WG). IECON 2008: 34th Annual Conference of IEEE on Industrial Electronics, Orlando, 10-13 Nov., 2008, pp. 2094-2099 doi:10.1109/IECON.2008.4758280

This Conference Paper is brought to you for free and open access by the School of Electrical and Electronic Engineering at ARROW@TU Dublin. It has been accepted for inclusion in Conference papers by an authorized administrator of ARROW@TU Dublin. For more information, please contact arrow.admin@tudublin.ie, aisling.coyne@tudublin.ie,gerard.connolly@tudublin.ie.

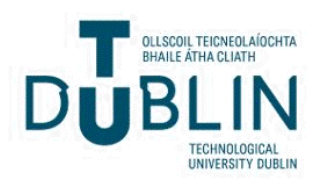




\section{Authors}

N. G. Jayanti, Malabika Basu, Kevin Gaughan, and Michael Conlon

This conference paper is available at ARROW@TU Dublin: https://arrow.tudublin.ie/engscheleart/107 


\title{
A new configuration and control of doubly fed induction generator (UPQC-WG)
}

\author{
School of Electrical Engineering Systems \\ Dublin Institute of Technology \\ Kevin Street, Dublin-8, Ireland
}

Jayanti N. G., Student Member, IEEE, Malabika Basu, Member, IEEE, Kevin Gaughan and Michael F. Conlon

\begin{abstract}
The paper presents detailed simulation based analysis and investigation on grid code compliance of a new configuration of a 2 MW Doubly Fed Induction Generator. The converters of DFIG are connected and controlled to function like a Unified Power Quality Conditioner (UPQC). One of the converters is connected in series with the stator terminals and acts to maintain the stator voltage at a predetermined value. It can also transfer power to or from the rotor side converter through the common DC link. The other converter is connected to the rotor like a conventional DFIG and is controlled to maintain appropriate rotor currents to establish the operating point based on the input mechanical torque and reactive power set point at the grid connection. The generator performs satisfactorily under steady state and grid fault condition both in the super and sub synchronous speed range. The newly designed machine is Irish grid code compliant.
\end{abstract}

\section{INTRODUCTION}

$50 \%$ of wind generators installed worldwide are Doubly Fed Induction Generators (DFIG) [1]. They are preferred over fixed speed generators for several reasons such as efficient energy capturing from wind, reduced stress on turbine and decoupled control over real and reactive power output [2][4]. A conventional DFIG consists of a wound rotor induction machine and two back to back connected converters in parallel to the grid, to transfer the power to and from the rotor. The converters are generally rated in the range of 25 to $30 \%$ of the rating of the machine. The converters are sensitive to high voltage and currents that might be induced during a grid side disturbance in this type of generator. The new grid codes for wind which are effective in recent years all over the world requires the wind generators to remain connected to the grid and assist to achieve fault ride through. This requirement poses the greatest challenge to the DFIG type of generators since protection of the converters under such situation is very crucial. Unless special protection measures are taken, operation of the generator under low grid voltage condition can cause damage to the converter system of the DFIG [5]-[8]. Typically a crow bar circuit is connected at the rotor converter to create the short circuit to protect the rotor side converter from over current and over voltages during grid side fault. The generator works like a fixed speed machine and the grid side converter is operated like a STATCOM in VAR control mode to assist fault ride through [9]. Different type of converter protection and fault current limiters are discussed in [6]-[8].
In this paper, a new configuration and control of DFIG converters is presented. The grid side converter of the DFIG is connected in series with the stator terminals and controlled to work like a Dynamic Voltage Restorer (DVR) during grid side faults. The rotor side converter is connected in shunt like a conventional DFIG. The structure and control of the converters is similar to that of a Unified Power Quality Conditioner (UPQC) [10],[11], hence the new generator is referred as UPQC integrated Wind Generator (UPQC-WG). Similar structure of DFIG has bee reported in [7] and [8]. In [8] there are two converters connected to the grid side of the generator. One of the converters is connected in shunt like a conventional DFIG. The other converter is connected in series with the grid and stator and put into action only during grid side fault to reduce the fault currents. Under steady state condition, the structure and control of the generator is same as any conventional DFIG. In [7], the series converter is utilized to do the power transfer and stator voltage regulation. The structure in [7] is the same as reported here, but the control of DC link voltage and hence the power transfer and stator voltage regulation are done by controlling the individual phase voltages. The work has not been reported in detail and it is important to consider a standard network with a voltage sag profile corresponding to any standard grid code for investigating the generator performance.

\section{Structure AND CONTROL OF UPQC-WG}

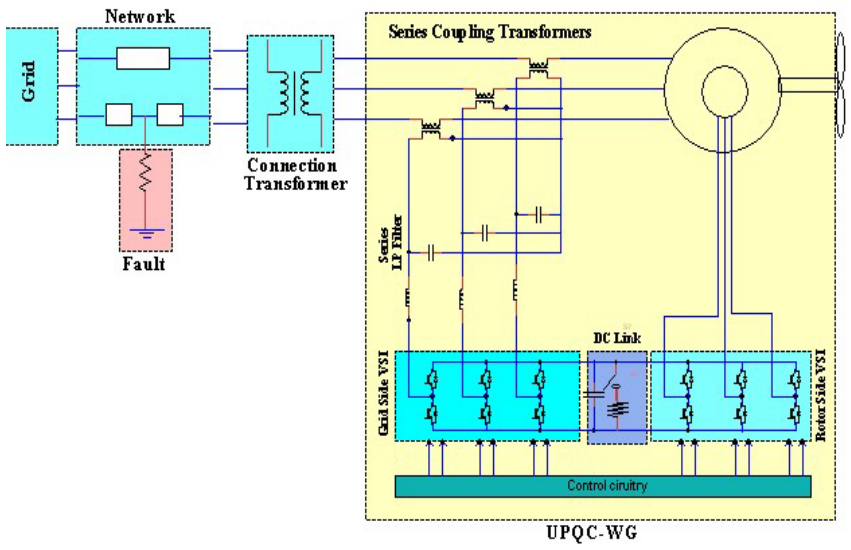

Fig. 1. Power system with UPQC-WG 


\section{A. Structure of UPQC-WG}

The Structure of UPQC-WG is shown in Fig. 1. The structure is similar to a DFIG except the grid side converter is connected in series with the stator before it is connected to the grid through a connection transformer. The rotor side converter controls the real and reactive power output to the grid according to the maximum power tracking curve designed for the generator. The grid side converter has two responsibilities. During the steady state operation, it injects appropriate voltage in-phase with the grid and the stator voltage in order to transfer appropriate power from the rotor to the grid through the DC link capacitor, thereby maintaining a constant DC link voltage. During a grid side fault, depending on the severity of the voltage sag, the grid side converter injects an appropriate voltage to compensate for any balanced or unbalanced sag and establishes a stable operating point for the generator. Under any severe voltage sag condition, when the DC link voltage tends to rise above $1.25 \mathrm{pu}$, the DC link voltage control is made ineffective and a chopper circuit is connected in parallel to the DC link capacitor to clamp the voltage at $1.25 \mathrm{pu}$.

\section{B. Control of UPQC-WG}

The wound rotor induction machine is modeled with classical dynamic machine equations in vector form given in (1)-(10) [12]. The real and reactive power can be calculated by (11) \& (12).

$v_{q s}=R_{s} i_{q s}+\frac{\omega}{\omega_{b}} \psi_{d s}+\frac{1}{\omega_{b}} \frac{d \psi_{q s}}{d t}$

$v_{d s}=R_{s} i_{d s}-\frac{\omega}{\omega_{b}} \psi_{q s}+\frac{1}{\omega_{b}} \frac{d \psi_{d s}}{d t}$

$v_{q r}^{\prime}=R_{r} i_{q r}^{\prime}+\left(\frac{\omega-\omega_{r}}{\omega_{b}}\right) \psi_{d r}^{\prime}+\frac{1}{\omega_{b}} \frac{d \psi_{q r}^{\prime}}{d t}$

$v_{d r}^{\prime}=R_{r} i_{d r}^{\prime}-\left(\frac{\omega-\omega_{r}}{\omega_{b}}\right) \psi_{q r}^{\prime}+\frac{1}{\omega_{b}} \frac{d \psi_{d r}^{\prime}}{d t}$

$\psi_{q s}=X_{l s} i_{q s}+X_{m}\left(i_{q s}+i_{q r}^{\prime}\right)$

$\psi_{d s}=X_{l s} i_{d s}+X_{m}\left(i_{d s}+i_{d r}^{\prime}\right)$

$\psi_{q r}^{\prime}=X_{l r} i_{q r}^{\prime}+X_{m}\left(i_{q s}+i_{q r}^{\prime}\right)$

$\psi_{d r}^{\prime}=X_{l r} i_{d r}^{\prime}+X_{m}\left(i_{d s}+i_{d r}^{\prime}\right)$

$T_{e}=\psi_{d s} i_{q s}-\psi_{q s} i_{d s}$

$\omega_{r}=\frac{1}{2 H}\left(T_{e}-T_{m}\right)$

$P_{s}=v_{d s} i_{d s}+v_{q s} i_{q s}$

$Q_{s}=v_{q s} i_{d s}-v_{d s} i_{q s}$

$\omega$ is the speed of the reference frame. Here a synchronous reference frame is considered. $\omega_{\mathrm{b}}$ is the base speed $\left(2 * \mathrm{pi}{ }^{*} \mathrm{f}\right.$, and $\mathrm{f}=50 \mathrm{~Hz}) . \omega_{\mathrm{r}}$ is the rotor speed. The terms with subscript ' $\mathrm{r}$ ' are rotor parameters, ' $\mathrm{m}$ ' are mutual parameters and subscript with ' $\mathrm{s}$ ' are stator parameters. The real power transferred to the grid by a UPQC-WG can be given as summation of power generated in the stator circuit and rotor circuit as given in (13). The rotor power which is slip dependent is generated during super-synchronous operation and absorbed during sub-synchronous operation.

$P_{\text {grid }}=P_{\text {stator }}-$ slip $* P_{\text {rotor }}$

The rotor side converter control is represented in the block diagram in Fig. 2. The d-q control is developed based on stator flux orientation of the voltage and current vectors which results in decoupled control of stator side real and reactive power. More details on the stator flux orientation and the stator flux angle estimation can be found in [3]. The transformations applied on the machine equations yield direct relation between electromagnetic torque and q-axis rotor current as shown in (14). (14) is derived from (1), (5) and (9). (15) is derived from (1), (6) and (12). The stator resistance is neglected while deriving these two equations.

$T_{e}=-\left(\frac{X_{m} i_{q r}^{\prime}}{\left(X_{l s}+X_{m}\right)}\right)\left(v_{q s} \frac{\omega}{\omega_{b}}\right)$

$Q_{s}=v_{q s}\left(\frac{v_{q s} \frac{\omega}{\omega_{b}}}{X_{m}+X_{l s}}-\frac{X_{m}}{X_{m}+X_{l s}} i_{d r}^{\prime}\right)$

The electromagnetic torque demand based on the measured rotor speed is looked up with a maximum power tracking curve. The quadrature axis rotor voltage is calculated in such a way that the quadrature axis rotor current establishes the electromagnetic torque in the stator. And similarly the transformations applied yield direct relation between $\mathrm{d}$ axis rotor current and reactive power on the grid side of the generator as shown in (15). A unity power factor condition is imposed through proper adjustment of $\mathrm{d}$ axis rotor voltage. The feed forward voltage terms $\left(\mathrm{V}_{\mathrm{qFF}} \& \mathrm{~V}_{\mathrm{dFF}}\right)$ as given in equation (16) and (17) are added to assist PI controllers in calculating $\mathrm{d}$ and $\mathrm{q}$ rotor voltages.

$$
\begin{aligned}
& V_{q F F}=R_{r} i_{q r}^{\prime}+\left(\frac{\omega-\omega_{r}}{\omega_{b}}\right)\left[\left(X_{l r}+X_{m} \frac{X_{m}^{2}}{X_{l s}+X_{m}}\right) i_{d r}^{\prime}+\frac{X_{m}}{X_{l s}+X_{m}} v_{q s} \frac{\omega_{b}}{\omega}\right] \\
& V_{d F F}=R_{r} i_{d r}^{\prime}-\left(\frac{\omega-\omega_{r}}{\omega_{b}}\right)\left(X_{l r}+X_{m}-\frac{X_{m}^{2}}{X_{l s}+X_{m}}\right) i_{q r}^{\prime}
\end{aligned}
$$




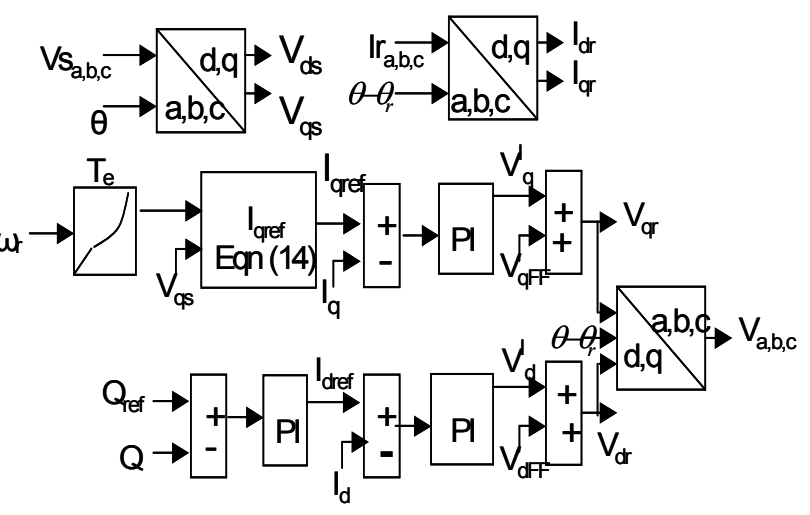

Fig 2. Control of rotor side converter

The grid side converter is controlled to transfer appropriate power to and from the DC link capacitor. The DC link model can be seen in Fig. 3. The variation in the DC link voltage is the direct measure of the real power transfer to or from the rotor. Therefore, the DC link voltage is calculated like shown in Fig. 3 with the help of $\mathrm{AC}$ side power difference between the two converters. A PI controller is applied to calculate the appropriate voltage $\left(\mathrm{V}_{\mathrm{inj} 1}\right)$ to be injected to keep the DC link voltage constant hence transfer the appropriate power during steady state operation. The output of the PI controller is limited to $25 \%$ of the nominal value of the voltage, considering $25 \%$ speed variation from synchronous speed. The injected voltage $\left(\mathrm{V}_{\mathrm{inj} \text { a,b,c }}\right)$ of the grid side converter is a combination of feed-forward terms $\left(\mathrm{V}_{\text {ref }}-\mathrm{V}_{\text {positive }}, \mathrm{V}_{\text {negative }}\right.$, and $\left.\mathrm{V}_{\text {zero }}\right)$ and the output of the PI controller $\left(\mathrm{V}_{\text {inj1 }}\right)$. Under steady state operation, the feed-forward term is nil. The voltage output of the PI controller is injected in-phase with the positive sequence voltage of the grid. The stator voltage is the vector sum of the grid and the injected voltage. It has to be noted that during the steady state operation, depending on the speed of the rotor, the stator voltage can be lower or higher than $1 \mathrm{pu}$.

During a balanced/unbalanced grid voltage sag condition, feed-forward terms (difference between reference voltage and positive sequence, negative sequence and zero sequence terms) are added to the grid voltage to establish pre-fault condition at the stator terminals. During a severe voltage sag, the DC link control and the stator terminal voltage control simultaneously can act contradictory to each other because of different control objectives. The DC link voltage control may fail due to excessive dumping of real power by grid side converter, depending on the severity of the fault. To prevent this, an additional chopper circuit comes in to action to bypass the additional real power. The chopper is put in to action as soon as the average value of the DC link voltage reaches the threshold value (1.25 pu), and the DC link voltage is clamped at that value. Since the upper and lower limit of the PI controller to control the DC link voltage is fixed at $25 \%$ of the nominal voltage, the overall voltage controller always maintains the stator voltage at least at $75 \%$ of the nominal voltage value at any condition. Simulation model of the system shown in Fig. 1 has been developed in SimPowerSystem toolbox of MATLAB Simulink.

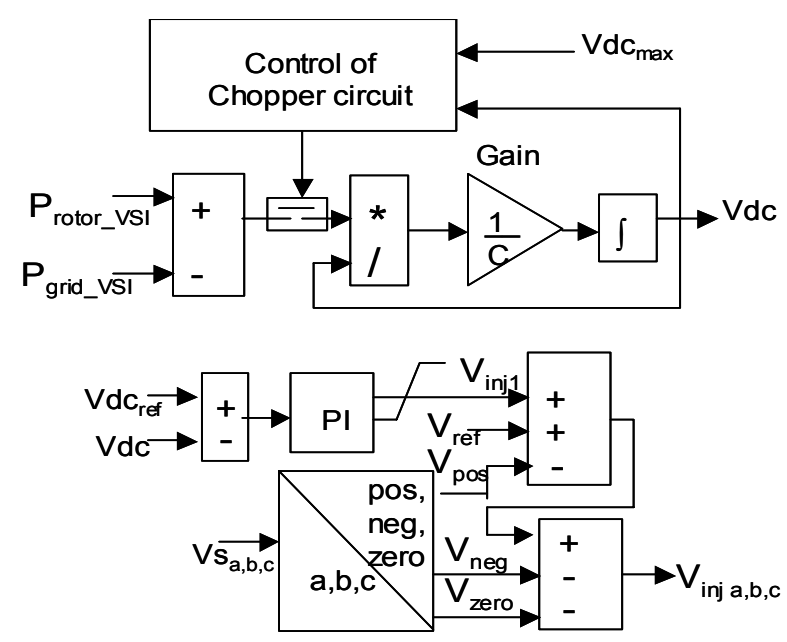

Fig. 3. Control of grid side converter

Average modeling technique of converters is followed in the model where actual switching of converters are not represented. The machine and the network parameters are given in the Appendix. The details on maximum power tracking curve can be found in [13]. Balanced and unbalanced faults of varying severity are created in the model by grounding the midpoint of one of the transmission lines though appropriate fault impedance.

\section{RESULTS}

The performance of UPQC-WG during steady state operating condition and during occurrence of balanced and unbalanced faults are discussed in this section.

\section{A. Steady state performance}

The steady state operation of the UPQC-WG under super synchronous and sub synchronous speed range can be seen in Fig. 4. The generator is initialized at synchronous speed at 0 second. At 2 second a mechanical torque set point of $-0.83 \mathrm{pu}$ is fed to the generator. According to the maximum power tracking curve the operating point of $1.2 \mathrm{pu}$ speed of rotor feeding 1 pu power to the grid is established. The grid power $(-1 \mathrm{pu})$ is the combination of rotor (-0.17) and stator power (0.83 ). At 30 second a mechanical torque set point of -0.36 corresponding to a rotor speed of $0.8 \mathrm{pu}$ is provided in the model. -0.29 pu real power is transferred to the grid, which is a combination of stator $(-0.36)$ and rotor $(0.07)$ power. The variation of the stator terminal voltage can be seen in the third plot of Fig. 4. For a $20 \%$ speed variation around synchronous speed, the stator terminal voltage varies between $0.84 \mathrm{pu}$ to $1.23 \mathrm{pu}$. Also the grid current during speed variation from super synchronous to sub synchronous speed can be observed in the last plot of Fig. 4. The grid side converter which is 
connected in series must be rated appropriately to handle this current.
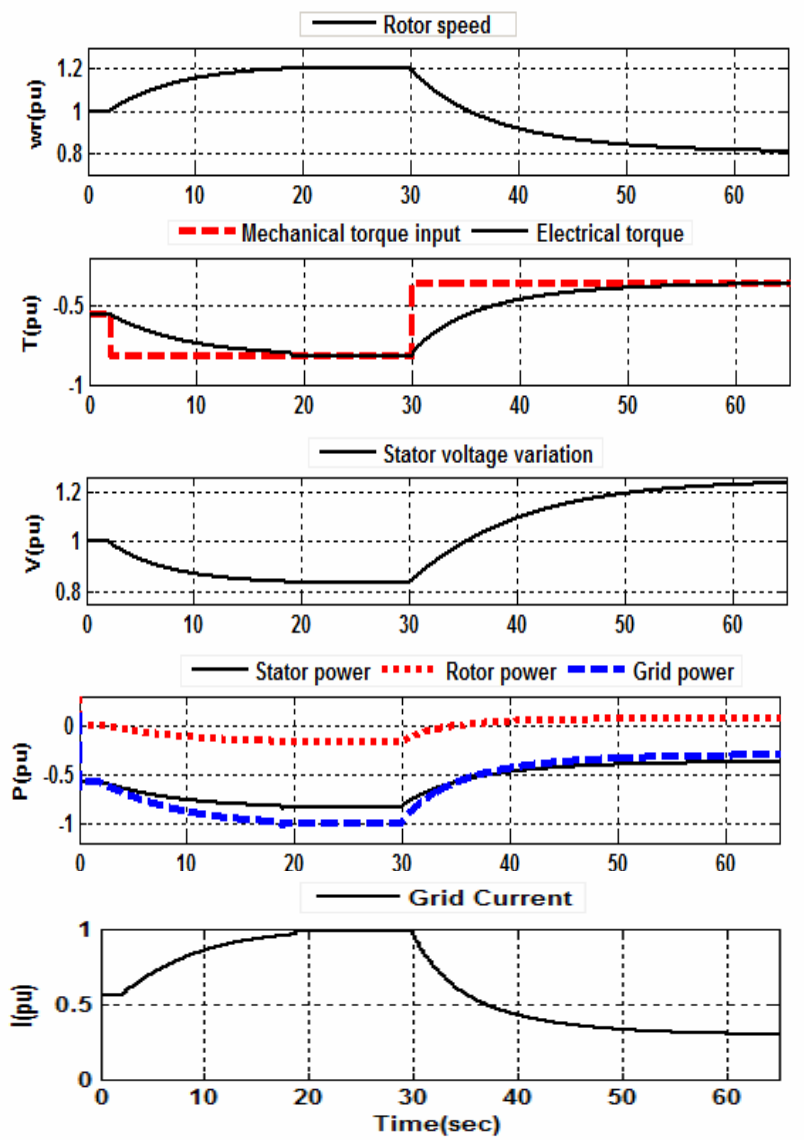

Fig. 4 Super and sub synchronous operation of UPQC-WG

\section{B. Performance under grid side faults}

The performance of UPQC-WG under balanced and unbalanced grid side faults is presented here. The machine is operating at a mechanical torque of $-0.83 \mathrm{pu}, 1.2 \mathrm{pu}$ rotor speed and delivering $1 \mathrm{pu}$ power to the grid. A three phase fault is created at 30 second by grounding the midpoint on one of the transmission lines through fault impedance such that a balanced voltage sag to $15 \%$ ( $85 \%$ voltage dip) is created at low voltage side of the grid connection transformer. The sag profile created is in accordance with the Irish Grid code requirements [14]. The fault is cleared at 30.625 second. The grid side converter controls the stator terminal voltage to remain at $75 \%$ of the nominal value. The electrical and mechanical torque mismatch is avoided since the prefault torque condition is re-established by the stator. The generator continues to work in the same fashion as pre-fault condition. The grid voltage, the stator voltage and the electrical torque can be seen in Fig. 5. Since the stator terminal voltage and the electrical torque conditions are reestablished, the rotor current does not increase above the converter capacity on occurrence of the fault and hence the rotor converter does not have to be disconnected under fault condition. The grid side converter acts to restore the stator terminal voltage.
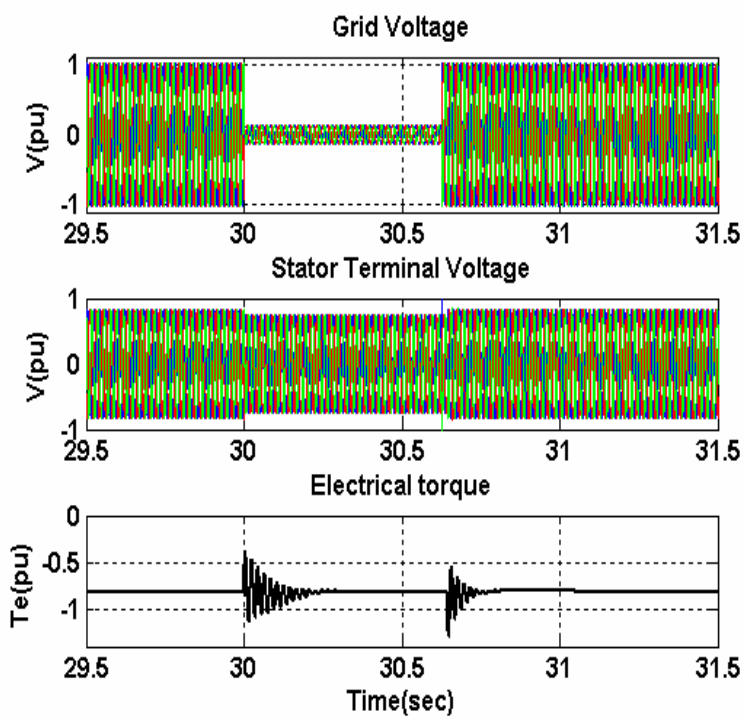

Fig. 5. Grid side, stator voltages and electrical torque during a 3-phase fault, under super-synchronous operation

Under such situation, the chopper connected along with the DC link comes into action to clamp the DC voltage at the threshold value as soon as the average of DC link voltage reaches it and the DC link voltage control from the grid side converter becomes ineffective. Here a DC voltage threshold value of $1.25 \mathrm{pu}$ is set for the chopper control. The power flow, the rotor current and the DC link voltage can be seen in Fig. 6. The power delivered to the grid is proportional to the voltage retained at the grid. The fault ride through achieved by the generator can be well appreciated with Fig. 5 and 6 .
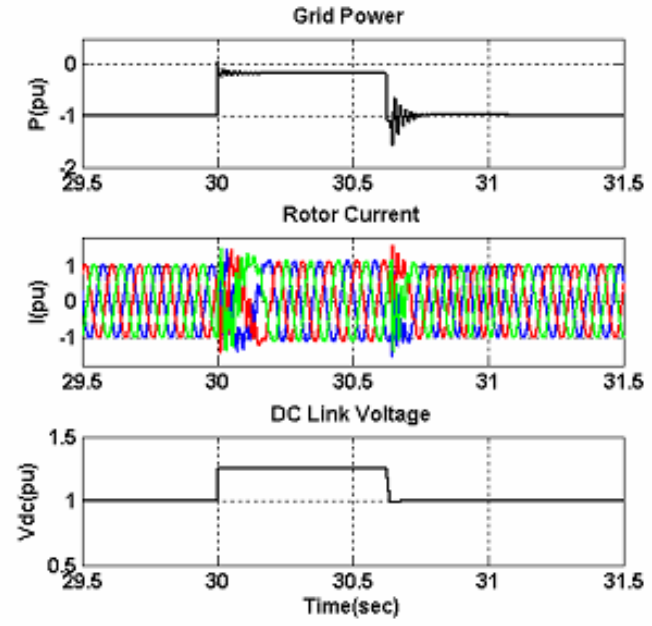

Fig. 6. Grid, stator and rotor power, rotor current and DC link voltage during three phase fault, under supersynchronous operation 
The same fault condition is repeated in the interval of 4040.625 second for a sub synchronous speed of operation. The machine is operating at mechanical torque of $-0.45 \mathrm{pu}$ and rotor speed of 0.89 , delivering 0.4 pu power to the grid. The grid voltage, the stator voltage and the electrical torque can be seen in Fig. 7.
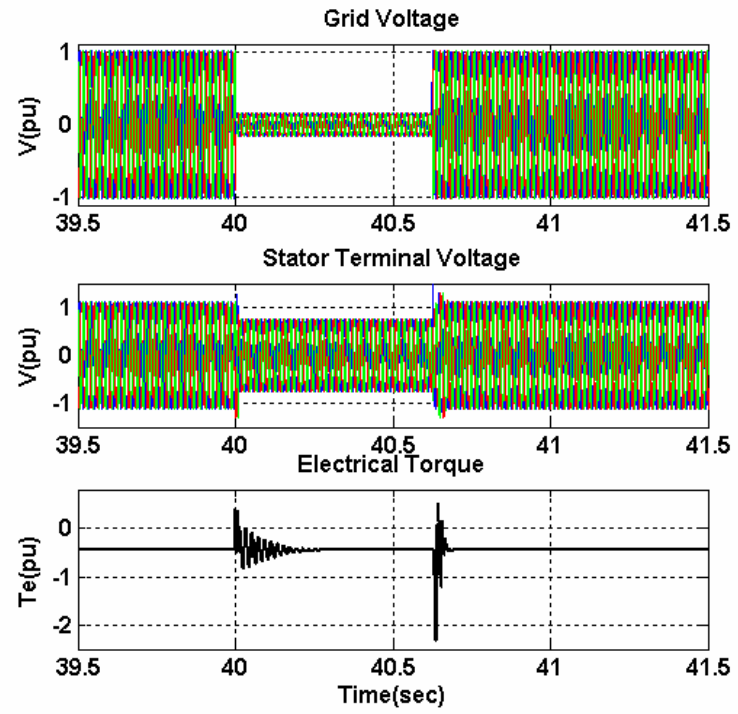

Fig. 7. Grid side, stator voltages and electrical torque during a 3-phase fault, under sub-synchronous operation

The power flow, the rotor current and the DC link voltage can be seen in Fig. 8.
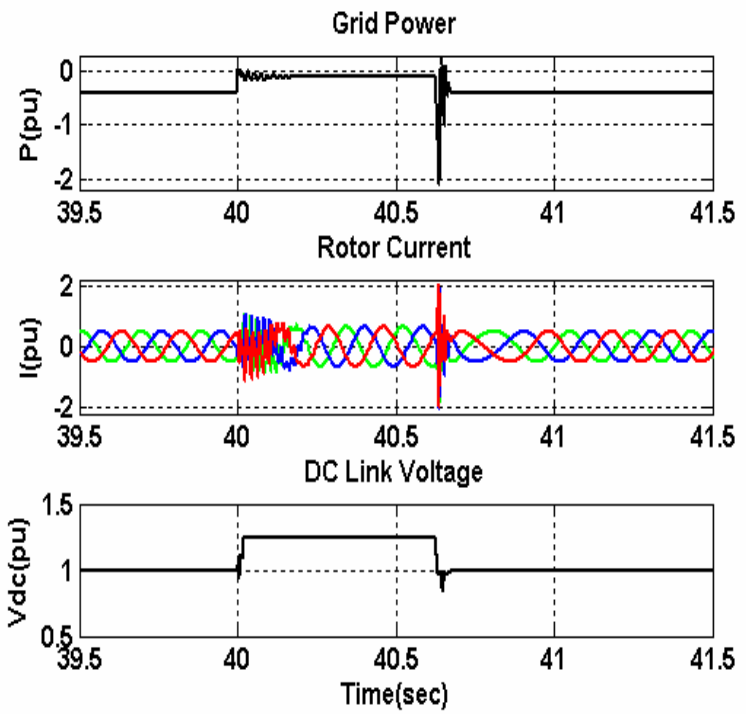

Fig. 8. Grid, stator and rotor power, rotor current and DC link voltage during three phase fault, under sub-synchronous operation

An unbalanced grid side fault (Line-Line-Ground) is created at 30 second and cleared at 30.625 second when machine operates at -0.83 mechanical torque and 1.2 pu rotor speed and delivering $1 \mathrm{pu}$ power to the grid. The grid voltage profile, stator terminal voltage and power flow can be seen in fig. 9 . With the sequence analysis based controller explained in section II, a balanced condition is established at the stator terminals by injecting appropriate positive, negative and zero sequence voltages. The stator terminal voltage is maintained at $75 \%$ of the nominal value under fault condition.
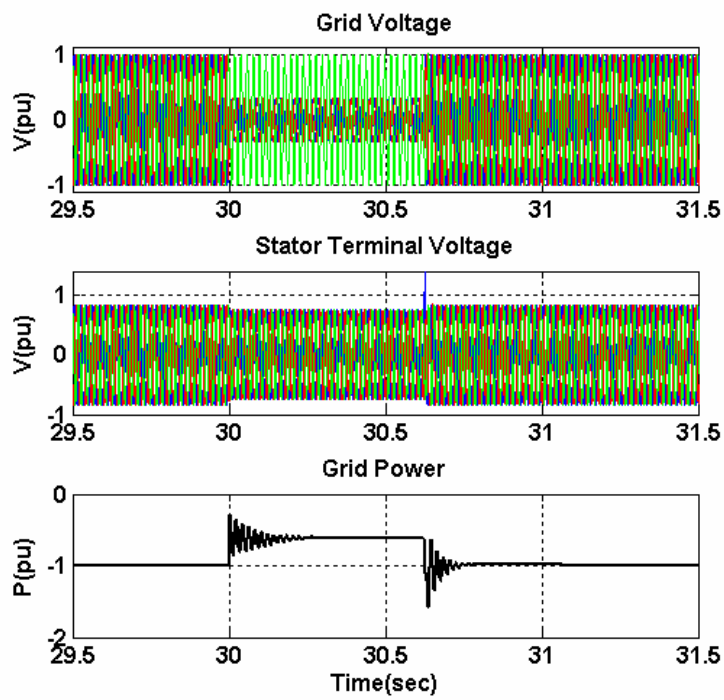

Fig. 9. Grid side, stator voltages and power flow during a LL-G fault, under super-synchronous operation

\section{CONCLUSIONS}

A new configuration and control for a Doubly Fed Induction Generator, UPQC-WG is proposed and the performance under normal operating condition and severe grid side fault condition is presented in the paper. The model is validated for the specified voltage profile under the Irish grid code. The grid side converter is controlled to restore the stator terminal voltage during grid side fault and hence reduces the fault current. Therefore, disconnection of the rotor side converter will not be necessary during any severe grid side fault. The results obtained from the simulation are promising.

\section{APPENDIX}

System parameters

Base value considered are $V_{\text {base }}=690 \mathrm{~V}, S_{\text {base }}=2 \mathrm{MW}$

\section{Machine parameters (in pu)}

Stator resistance $\left(R_{S}\right)=0.00488$

Rotor resistance $\left(R_{r}\right)=0.00549$

Stator reactance $\left(X_{l s}\right)=0.09241$

Rotor reactance $\left(X_{l r}\right)=0.09955$ 
Magnetising reactance $\left(X_{m}\right)=3.95$

Lumped inertia constant $(H)=3.5 \mathrm{~s}$

Transformer: $690 \mathrm{~V}: 11 \mathrm{kV}, 5 \%$

Short Circuit $\boldsymbol{M V A}$ at low voltage side of grid connection transformer $=20 \mathrm{MVA}$

$X / R$ ratio of network $=5$

\section{REFERENCES}

[1] F. Blaabjerg and Z. Chen, Power electronics for modern wind turbines, Morgan and Claypool publishers 2006.

[2] V. Akhmatov, "Variable -speed wind turbines with doubly-fed induction generators, Part I : Modelling in dynamic simulation tools", Wind engineering, Vol 26, No. 2, 2002, pp. 85-108.

[3] B. H. Chowdhury and S. Chellapilla, "Doubly-fed induction generator control for variable speed wind power generation", Electric Power Systems Research, vol. 76, 2006, pp. 786-800.

[4] A. D. Hansen, P. Sorenson, F. Iov and F. Blaabjerg, "Control of variable speed wind turbines with doubly fed induction generator", Wind Engineering, Vol. 28, No. 4, 2004, pp. 411-434.

[5] Y. Zhou, P. Bauer, J. A. Ferreira and J. Pierik, "Control of DFIG under unsymmetrical voltage dip", IEEE Power Electronics Specialist Conference (PESC), Jun. 2007,pp. 933-938.

[6] I. Erlich, H. Wrede and C. Feltes, "Dynamic behavior of DFIG-based wind turbines during grid fault", Power
Conversion Conference (PCC), Apr. 2007, pp. 11951200.

[7] N. N. Joshi and N. Mohan, "New scheme to connect DFIG to power grid", IEEE Industrial Electronics (IECON), Nov. 2006, pp. 4225-4230.

[8] P.S. Flannery and G. Venkataramanan, "Evaluation of voltage sag ride-through of a doubly fed induction generator wind turbine with series grid side converter", IEEE Power Electronics Specialists Conference (PESC), Jun. 2007, pp. 1839-1845.

[9] A. D. Hansen and G. Michalke,"Voltage grid support of DFIG wind turbines during grid faults", accessed from internet at www.risoe.dk/rispubl/art/2007_148 paper.pdf on $30^{\text {th }}$ Apr. 2008.

[10] Gu Jianjun, $\mathrm{Xu}$ Dianguo, Liu Hankui and Gong Maozhong, "Unified Power Quality Conditioner (UPQC) : the principle, control and application", IEEE Power Conversion Conference 2002, PCC-Osaka, Vol. 1, pp 80-85.

[11] H. Akagi, "New trends in active filters for power conditioning", IEEE Transactions on Industry Applications, Vol. 32, No. 6, 1996, pp 1312-1322.

[12]P. C. Krause, O. Wasynczuk and S. D. Sudhoff, Analysis of electric machinery and drive systems, second edition, IEEE press, Wiley Interscience, 2002.

[13] J. B. Ekanayake, L. Holdsworth , X. G. Wu , N. Jenkins, "Comparison of Fixed Speed and Doubly-Fed Induction Wind Turbines During Power System Disturbances", IEE Proc - Gener. Transm. Distrib. Vol. 150, No. 3, May 2003 pp 343-352.

[14] EirGrid Grid Code version 2.2 modified on August $31^{\text {st }}$ 2007, available at www.eirgrid.com , ESB National Grid Website 